\title{
Teatro como elo entre culturas: a experiência do corpo como narrador de histórias na aldeia Jaguapiru em Dourados - MS
}

Marco Aurélio Poli Dolci Flávia Janiaski Vale

DOI: $10.5965 / 2358092521232020102$

1 Bacharel e Licenciado em Artes Cênicas pela Universidade Federal da Grande Dourados (UFGD). Ator, dramaturgo, diretor e professor de Teatro/Arte no ensino fundamental II e médio nas escolas estaduais de Araraquara e Boa Esperança do Sul/São Paulo. E-mail: marcopoli@live.com 2 Doutora em Artes Cênicas pela Universidade Federal da Bahia (UFBA). Professora Adjunta da Universidade Federal da Grande Dourados (UFGD) no Curso de Licenciatura e Bacharelado em Artes Cênicas. E-mail: flajaniaski@hotmail.com 


\section{RESUMO}

É possível pensar em um teatro comunidade em que não são ouvidas as vozes dos integrantes pertencentes a este espaço? Acreditamos que não. Para se trabalhar em comunidade é preciso escolher o caminho da troca e do respeito, delineando um projeto que esteja alicerçado no reconhecimento de que ambas as partes possuem cultura e conhecimentos prévios e distintos. Partindo dessa perspectiva, o presente artigo escrito a quatro mãos - apresenta uma reflexão sobre a oficina realizada no ano de 2019 na Aldeia Jaguapiru (Dourados/MS), com um grupo de 10 crianças entre 6 e 12 anos. A oficina fez parte da disciplina de estágio curricular supervisionado da Graduação de Artes Cênicas da Universidade Federal da Grande Dourados - UFGD. O Sistema do Movimento de Rudolf Laban como propulsor para a expressividade do corpo que narra foi a metodologia utilizada para auxiliar no compartilhamento da dramatização entre culturas distintas. Os apontamentos e as descobertas aqui expostos visam inspirar outros trabalhos em comunidade que reflitam o fazer democrático do teatro e o respeito aos sujeitos.

Palavras-chave: sistema do movimento, teatro comunidade, construção de narrativas.

\section{ABSTRACT}

Is it possible to think of a community theater where the voices of the members belonging to this space are not heard? We do not think so. In order to achieve an effective work in a community, it is necessary to choose the path of exchange and respect, to outline a project that is capable of recognizing that both sides have a previous and distinct culture and knowledge. Based on this thought, this article - written in four hands - presents a reflection on a workshop held 
in 2019 in Aldeia Jaguapiru (Dourados), with a group of 10 children between 6 and 12 years old. The workshop was part of an internship inside of graduation in Drama at the Universidade Federal da Grande Dourados - UFGD. Rudolf Laban's Movement Analysis as an impulsive of expressiveness of the body that narrated stories was used as an approach to assist in the sharing of dramatization between different cultures. The notes and discoveries exposed here aim inspired other works in the communities that reflect the democratic doing of theater and respect for the subjects.

Keywords: Laban movement analysis, community theater, construction of narratives.

\section{O ESPAÇO COMUNIDADE E SUA RELAÇÃO COM O TEATRO}

De acordo com Paulo Freire (1980, p. 119) o pensar é ato de trocas coletivas, não há como pensar pelos outros, para os outros ou sem os outros "a investigação do pensar do povo não pode ser feita sem o povo, mas com ele, como sujeito de seu pensar". Acreditamos que o teatro comunidade compartilha deste princípio, é necessário considerar a comunidade a partir de sua cultura, seus hábitos, seus costumes e suas rotinas, isto é, fazê-la sujeito das próprias práticas teatrais. É preciso, como sugere Freire, que as vozes da comunidade sejam ouvidas com o objetivo de estabelecer processos de trocas e de interações para construção de conhecimentos.

Partindo destes princípios confeccionamos um projeto de ensino de teatro para crianças de 6 a 10 anos pertencentes a uma comunidade indígena da Aldeia Jaguapiru em Dourados/ MS. Este projeto fez parte da disciplina de estágio curricular supervisionado, da licenciatura de Artes Cênicas da UFGD, que prevê a realização de 30 horas de regência de teatro no ensino formal ou não formal. 
Na disciplina o discente tem autonomia de decidir o local e a temática que gostaria de pesquisar. Desta forma, a escolha do local de realização da prática de estágio partiu do discente e se deu pelos seguintes motivos: primeiramente pelos anseios de pesquisar e de experimentar ações teatrais em espaços não formais; segundo pelo fato de que as crianças que participaram da oficina nunca haviam experimentado o teatro como prática, nem mesmo na escola em que estudam; terceiro pela relação de amizade prévia entre estagiário e líder da aldeia, esta amizade permitiu que o estágio fosse realizado na igreja (localizada no quintal da casa da líder), assim como permitiu a aproximação com a comunidade e a divulgação da oficina. A partir destas escolhas, foi importante compreender com que tipo de comunidade estávamos trabalhando, para em seguida pensar qual processo teatral iríamos realizar. Desde o primeiro momento foi decidido - pelo estagiário e orientadora - que a realidade da comunidade seria respeitada.

O que define uma comunidade? Sua localização? A associação de pessoas em torno de um objetivo comum? O local de nascimento e a descendência? De acordo com Anthony Cohen (1985, p. 15), uma comunidade não se define apenas pelo conjunto de pessoas que residem em uma mesma localidade, mas diz respeito à entidade à qual as pessoas se sentem pertencentes, ultrapassando as relações de parentesco: "é a arena onde as pessoas adquirem suas experiências mais fundamentais e substanciais da vida social, fora dos limites do lar".

Baz Kershaw (1992) distingue dois tipos de comunidade: a de local e a de interesse. A primeira diz respeito a uma teia de relações em local geográfico específico e comum; a segunda pode ser caracterizada por pessoas de localidades diferentes, mas que compartilham um mesmo ideal ou identidade. No caso da comunidade escolhida para a realização do projeto a determinação de comunidade passa pelo âmbito geográfico (pois todos residem em um mesmo local), pela questão de interesses e metas comuns (pois partilham da mesma cultura e história de vida), e pela questão étnica (por fazerem parte da mesma tribo indígena). 
Em relação ao tipo de projeto que queríamos desenvolver na Aldeia Jaguapiru, recorremos a Márcia P. Nogueira que distingue três modelos de teatro na comunidade: teatro para comunidades; teatro com comunidades; e teatro por comunidades. $\mathrm{O}$ primeiro modelo diz respeito ao teatro realizado "por artistas para comunidades periféricas, desconhecendo de antemão sua realidade" (NOGUEIRA, 2009, p. 177), ou seja, os artistas realizam seu projeto e/ou seu espetáculo em determinada comunidade, sem conhecer seu contexto social e histórico. O segundo modelo, em contraponto ao primeiro, parte da "investigação de uma determinada comunidade para a criação de um espetáculo" (NOGUEIRA, 2009, p. 177), essa prática inclui conhecer e pensar nas características culturais, históricas e sociais da comunidade. Já o terceiro modelo integra a própria comunidade no processo de criação; este modelo tem influência direta de Augusto Boal e Paulo Freire, e parte de uma "perspectiva crítica ao teatro de mensagem [...] ela expressa os fundamentos da evolução do teatro de mensagem em relação ao teatro participativo" (NOGUEIRA, 2009, p. 177). Neste modelo os membros da comunidade são os próprios atores do trabalho, com o intuito de produzir um processo de conscientização através de uma prática dialógica.

Sob este prisma, podemos dizer que tentamos desenvolver um trabalho de teatro com e por comunidade, pois a aprendizagem teatral partiu da realidade e das histórias da comunidade, e foi criado e realizado em conjunto entre as crianças pertencentes da comunidade e o estagiário. As improvisações realizadas com as crianças emergiram de formas e materiais propostos pelos participantes. Desta maneira, nossa experiência do teatro com e por comunidade partiu de uma prática que tentou propor novos olhares e possibilidades do corpo que se expressa singularmente a partir de sua própria realidade e de um trabalho colaborativo. 


\section{O MOVIMENTO E SEUS ASPECTOS NO TEATRO}

Na confecção do projeto a ser desenvolvido na aldeia, desejávamos unir diversão e educação, por isso escolhemos o Sistema do Movimento de Rudolf Laban como metodologia nas práticas teatrais. O sistema poderia contribuir na expressividade das crianças e dos adolescentes pois coloca em diálogo a expressividade do gesto e a narração de histórias.

Rudolf Laban (1879-1958) foi bailarino, coreógrafo e arquiteto eslavo, dedicou sua vida aos estudos da expressividade do corpo na dança e no teatro. Por não aceitar o vazio que existia nas peças de teatro e de dança de sua época elaborou o que ficou convencionado como de Sistema do Movimento. "Arte do movimento é um termo usado para a reunião dos estudos propostos por ele, por meio da criação de nomenclaturas com noções que tratam dos infinitos elementos que podem ter um movimento, um gesto, uma ação, uma dança" (RENGEL et al, 2017, p. 18). Essa arte relaciona com o estado interior ou exterior do sujeito nas ações criadas, ou seja, trabalha-se a relação entre subjetividade e movimento. Com isso, Laban também procurou estabelecer um trabalho acessível para todas as pessoas, sem padronização de passos, pois, para o artista, a padronização prejudicaria a expressão.

De acordo com Laban (1978, p. 20-21), o conceito de movimento é mais do que é mostrado pela ação, ele vai revelar coisas distintas: "é o resultado, ou da busca de um objeto dotado de valor, ou de uma condição mental. Suas formas e ritmos mostram a atitude da pessoa que se move numa determinada situação. [...] O movimento pode ser influenciado pelo meio ambiente do ser que se move", ou seja, o movimento revela significado, sentindo e emoções para a expressão da arte teatral. O Sistema do Movimento identifica diversos aspectos do movimento, contudo, escolhemos trabalhar apenas três: esforço, ação e espaço.

Para refletir o movimento como um sistema gerador de comunicação não verbal, iniciaremos com a reflexão sobre o 
trabalho de uma das crianças participantes da oficina, que neste artigo chamaremos de Sol. Ela pode ser descrita como uma criança introvertida, nos primeiros encontros apresentou resistência em compartilhar as atividades propostas, expressar suas ideias e/ou suas sensações. No entanto, ao propormos um jogo onde o movimento deveria partir de estímulos provenientes de verbos (palavras que geram ações) Sol começou a se interessar e se permitiu fazer experimentações com o seu corpo.

Importante salientar que nas conversas após cada dinâmica Sol não conseguia identificar suas potencialidades, e revelava o sentimento de sempre estar fazendo a atividade proposta de forma errada, ou que não era capaz de criar movimentos. Parte desta cruel autocrítica era decorrente - segundo relato dela - da pressão e preconceito que sofria na escola ao ser chamada de "burra" pelas outras crianças.

Durante a oficina nosso trabalho foi tentar estimular a imaginação de cada participante através do contar vivências do cotidiano de cada criança, desta maneira cada um poderia fazer escolhas próprias do que compartilhar com o grupo. Como um dos objetivos era o corpo como narrador de histórias, para estimular primeiramente a criação dessa narrativa, sempre fazíamos conversas de como foi o nosso dia anterior, seja na escola ou em casa, o que mais gostávamos de fazer, quais personagens de filmes ou desenhos mais gostávamos. A partir disso, Sol aos poucos começou a participar das dinâmicas e contar histórias dos acontecimentos de seu dia a dia. Em uma dessas conversas, Sol contou ao grupo que na escola onde estuda, seus colegas sempre a excluíam ou a chamavam de burra, e por esta razão ela preferia não participar de alguns encontros ou jogos propostos, por acreditar não ser capaz de experimentar às propostas de criação com o corpo e imaginação. Aos poucos e através do estímulo do estagiário e dos colegas, Sol passou a confiar no grupo e a narrar suas vivências e preferências, tais como o seu amor pelos animais e que em seu quintal havia cachorros, galinhas, passarinhos e patos. Esse universo de sua vida real - os animais - sempre estavam presentes nas histórias por ela contada. 
A cada novo encontro Sol parecia mais confiante e passou a ser a criança que mais contava histórias e fazia os jogos propostos. Uma dinâmica que trouxemos para a oficina foi pedir as crianças que desenhassem os acontecimentos e/ou personagens das histórias criadas durante o encontro, assim como também em alguns encontros começávamos com os desenhos e a partir deles eram criadas histórias que posteriormente seriam narradas com seus corpos. Esta dinâmica foi importante, porque a partir delas é que as crianças (especialmente Sol) começaram a experimentar suas descobertas e narrações. A indicação dada era que para narrar às histórias era preciso utilizar os movimentos que trabalhávamos durante os encontros, ou seja, movimentos segundo as propostas de Laban.

Koudela e Almeida Junior (2015), coloca que o corpo está em constante comunicação com o outro e com o mundo, apesar disso, a linguagem física por muitas vezes passa desapercebida diante de nós. Nossos corpos estão sempre codificando sentimentos e pensamentos relacionados com a troca entre o que lhe é interno e o que lhe é externo. Tudo se torna visível, tudo se comunica corporalmente com ou sem expressão verbal. No corpo existe presença e este modifica o mundo. Sabemos que todas as nossas ações são movimentos, mas no teatro busca-se estados de energias que modificam nosso corpo e possibilitam formas de expressão não cotidianas.

Buscamos compreender com o sistema de Laban essas modificações corporais que geravam novas expressões para as crianças, e as contribuições desses estados para narrar a história O Peixinho Dourado ${ }^{3}$. Visto que ao utilizar os verbos enquanto estímulos em experimentação, uma "outra" energia - fora do cotidiano - se moldava com novos movimentos e a história ganhava mais vida e presença cênica. A história citada acima foi criada a partir de um dos jogos propostos durante a oficina. Foi solicitado a cada participante que criassem uma história usando apenas desenhos. Cada um recebeu papel e lápis e a instrução

\footnotetext{
3 História criada por uma das crianças durante a oficina e escolhida por todos para ser trabalhada e apresentada.
} 
de desenhar os acontecimentos e personagens que depois serviria de enredo para a construção de uma história.

Sol, a autora da história, criou seus personagens a partir de seu amor pelos animais, narrando um universo próprio da aldeia. As duas personagens principais da história eram uma muIher e uma criança indígena, que caminhavam por uma floresta e viam sempre às peripécias de um peixinho para sobreviver. Este peixinho, que era dourado, contava sempre com a ajuda de seus amigos: um coelho, um urso e alguns passarinhos; juntos eles lutavam contra as formiguinhas que não gostavam do peixinho. O personagem que dava nome a história estava com medo e triste porque foi retirado do rio para viver preso em um aquário, no final da história, com a ajuda de seus amigos e da menina, o peixinho voltou para o lugar que ele mais amava viver: o rio, que era seu lar. Todas as crianças gostaram da história e a escolheram para ser contada coletivamente, e posteriormente apresentada aos outros integrantes da aldeia.

Essa dinâmica que relaciona o interno e externo no Sistema do Movimento, é acentuada pelo esforço, e "Laban define esforço como o conjunto de impulsos interiores do qual o movimento se origina. O esforço humano varia em sua manifestação e é um conjunto de vários elementos compostos num número infinito de combinações" (ANDRADE, 2008, p. 172). No entanto, foram através de estímulos externos como músicas, textos, balões e fitas de crepom que os esforços foram gerados e estimulados e os participantes da oficina - cada um a seu tempo e autonomia - experimentaram como ações a expressividade do corpo e suas narrações.

Para efeito de exemplificação, trazemos aqui novamente o caso de Sol. Ao utilizar os objetivos propostos (balões e fitas de papel coloridos), ela precisou ir além do movimento e utilizar sua imaginação para dar vida e conduzir esses elementos que iam se transformando em personagens. Com um dos objetos em mãos e junto com o trabalho experimentado de alguns movimentos proposto a partir dos estudos sobre Laban, Sol realizava a narração da história com esses objetos que potencializaram seu corpo e deram mais energia para conduzir e mostrar 
os personagens criados por ela. Sua voz também se modificava conforme sua ação e a cada acontecimento da história, o que combina com o argumento de que "a experiência da imaginação do movimento e a memória do movimento são estímulos suficientemente poderosos para transformar combinações mais prolongadas de temas de estudo do movimento, que se tornam interessantes e agradáveis às crianças" (LABAN, 1990, p. 38). Ficou nítido com a oficina que ao trabalhar com indagações imaginativas no universo das crianças, elas potencializaram o corpo e conseguiram modificar e expressar novas formas pelo ambiente.

A ação é fundamental no sistema de Laban pois compõe a investigação da expressividade do corpo. O trabalho com as crianças sempre teve como foco essas ações, que serviam como estímulos e novas formas corporais de se comunicarem. Cada criança dava significados às ações no corpo de forma subjetiva e as expressava conforme suas próprias descobertas.

Outro fator de Laban trabalhado foi o espaço. Segundo o autor o espaço pode ser traduzido na ideia de que o indivíduo trabalhe os planos (alto, médio e baixo), as direções (direita, esquerda, frente e trás), as extensões (perto, normal, longe, pequeno e grande) e o caminho (direto, angular e curvo).

O lugar de Laban, o espaço de Laban, traz uma ideia de mundo, de se relacionar com pessoas e com o contexto no qual se está inserido. Com esse entendimento, o espaço, enquanto lugar, sempre configura uma espacialidade. A espacialidade, pode-se afirmar, é o que se configura no espaço (RENGEL, 2017, p. 39).

Esse conceito de espaço foi bastante provocado nas crianças, pois foi observada a necessidade delas conscientizarem seus corpos nesse lugar, em relação ao outro, ao objeto e ao texto. Nessas possibilidades foram propostas formas de perceber o espaço em situações não cotidianas, como relacionar a representação do corpo de animais e seus planos (alto, médio e baixo) em relação ao espaço que ele se encontra. 
Esses estímulos foram provenientes da história criada coletivamente pelas crianças, e eles acentuavam a experiência do espaço e os transportavam ao ambiente da história narrada de forma, "a reconhecer a estreiteza e a amplitude, e todos os diferentes lugares em torno de seu corpo para onde pode descolar-se" (LABAN, 1990, p. 28). Com esses propósitos, a experiência na aldeia funcionou como conscientização do seu espaço como comunidade e o teatro, segundo relato dos participantes, contribui para novas descobertas.

\section{AÇÃO COMO EIXO NARRADOR DO TEATRO NA COMUNIDADE}

No teatro, o termo ação aparece em várias discussões. Nesse caso iremos expor conceitos e refletir como a prática teatral ocorreu na Aldeia Jaguapiru. Vejamos algumas definições que contribuem para compor esse trabalho. Ação vem do grego que significa o mesmo que drama. O autor Martin Esslin esclarece que drama:

É ação mimética, ação que imita ou representa comportamentos humanos (à exceção dos poucos casos extremos de ação abstrata que já mencionei). O que é crucial é a ênfase sobre a ação. De modo que o drama não é simplesmente uma forma de literatura (muito embora as palavras usadas em uma peça, ao serem escritas, possam ser tratadas como literatura). O que faz com que o drama seja drama é precisamente o elemento que reside fora e além das palavras, e que tem de ser visto como ação - ou representado - para que os conceitos do autor alcancem sua plenitude (ESSLIN, 1978, p. 16).

Essa definição dialoga com as ações que eram propostas durante os encontros, foi necessário fazer uma adaptação dos termos que designam essas ações, para a linguagem das crianças, fazendo uso de analogias que as tornavam mais lúdicas, como: saltar, chicotear (corda), empurrar, forte (trator que empurra); os planos: alto (céu), médio (mesa) e baixo (terra); lon- 
ge (expandir/sol) e perto (retrair/lua), essas são algumas ações, segundo o Sistema do Movimento de Laban. No entanto, essas adaptações são importantes para aproximar a teoria com a prática, pegando como exemplo o termo "forte" (de Laban) quando dito às crianças, automaticamente elas relacionavam com alguém forte e não com a força do movimento. Mas, quando trocamos para o termo "trator que empurra" às crianças conseguiram estabelecer uma relação com seu cotidiano e entenderam seus corpos como um todo em forma de trator e a força que esta máquina tem para empurrar. Desta forma, quando as crianças fizeram o exercício elas de fato utilizaram a força como um todo para caminhar e fazer outras ações pelo espaço.

Dentre as práticas culturais e artísticas que uma comunidade desenvolve, experimentar o fazer teatral, como forma de reafirmar e de contar suas origens e suas histórias, contribui para novos olhares dos indivíduos desse local em relação ao seu eu e ao mundo, potencializando para seus desenvolvimentos de forma concreta para se posicionar com suas identidades em sociedade. O Sistema do Movimento de Laban propõe uma descoberta corporal que não impõe formas predeterminadas, mas dá espaço para a expressão e a produção de significados em relação a suas identidades e suas origens. Como aqueles percebidos nos momentos em que as crianças traziam, em suas experiências, imagens e símbolos indígenas. Era possível identificar a presença da cultura indígena em seus desenhos, como por exemplo o uso da representação do cocar, de flechas, da mandioca, etc., inseridos em ambientes que representavam aldeias e a natureza com muitas árvores e pássaros. Na parte prática com os movimentos, quando era pedido para experimentar pelo espaço às ações trabalhadas anteriormente segundo Laban, era possível observar a mistura desses elementos para narrar às histórias. É nessa perspectiva que o trabalho na aldeia com as ações de Laban se deu: por meio da colaboração em dar visibilidade a cada identidade de cada criança participante da oficina.

Retomando a transformação histórica dos modelos de teatro na comunidade apresentados por de Nogueira (2009) (Teatro para Comunidades; Teatro com Comunidades; Teatro por 
Comunidades), reiteramos que as experimentações do Sistema do Movimento de Laban realizadas pelas crianças refletem o que pode ser compreendido como um Teatro com e por Comunidades. Como sugere Nogueira (2009, p. 177) em sua definição de Teatro com Comunidade, na aldeia, foram as próprias crianças que criaram o espetáculo, pois elas mesmas sugeriam a linguagem, os conteúdos, os assuntos e as formas. E ao final da oficina foi apresentada uma história - O Peixinho Dourado - criada por Sol e construída em conjunto com o grupo a partir de elementos da cultura indígena, como por exemplo, a natureza, o amor a terra e o direito à liberdade. A questão que permeava a história era que cada "criatura" tem o direito de viver onde escolheu chamar de lar, ao lado de seus amigos e de tudo aquilo que lhe é familiar, até mesmo seus "inimigos" naturais como as formigas.

Se por um lado o trabalho de Laban é fomentar a sensibilização e a percepção de mundo, por outro, o teatro na comunidade busca, como aponta Nogueira (2009, p. 178) ser "porta-voz de assuntos locais, o que poderia contribuir para expressão de vozes silenciosas ou silenciadas da comunidade, como dizem muito autores, o teatro feito pela comunidade contribuiria para a contínua regeneração do espírito de comunidade". No caso da experiência com a aldeia, a corporalidade era o principal meio expressivo das crianças, por meio das experimentações corporais elas descobriam outras possibilidades de se expressarem e de narrarem suas histórias.

As vozes silenciosas apontadas por Nogueira (2009) ganharam vida na história criada coletivamente. Nos desenhos das crianças e na história criada por elas, recorrentemente apareciam as figuras da cultura indígena e os animais que fazem parte de seus imaginários e que compuseram o enredo. Isso pode ser um indício de como o corpo em movimento pode estimular a imaginação, e de como a imaginação pode criar corporalidades.

Resgatando o exemplo de Sol mencionado acima, é certo dizer que no início da oficina, ela refletia suas situações cotidianas, como uma ruptura de sua capacidade de ser o que ela quisesse ser, pois, segundo ela na escola, as outras crianças a chamavam de "burra" e afirmavam que ela não conseguia fazer 
as atividades das aulas. Porém sua capacidade cognitiva e imaginativa ficavam nítidas durante as atividades. O trabalho com o movimento fez com que Sol, ao decorrer dos dias, fosse se libertando dessas amarras negativas impostas por outras pessoas. Primeiramente ela encontrou na oficina um espaço para ter voz, ao se sentir segura dentro do espaço geográfico da aldeia e com seus pares, Sol foi capaz de falar sobre seus medos, as aflições vividas na escola e compartilhar seu cotidiano de forma lúdica, brincando e jogando com seus colegas através da prática teatral.

A cada encontro Sol ia se apropriando das ações e da história em forma de movimentos e com isso suas potencialidades expressivas eram observadas, era possível perceber como os seus movimentos estavam mais precisos. Em um dos exercícios Sol utilizou a ação de chicotear com a parte do texto que dizia: o passarinho voava. Nesse momento, ela começou a fazer os movimentos mais rápidos e ao mesmo tempo que dizia: "e voava, voava, voava bem alto". Tomamos isso como um indício de como o corpo em movimento, ou seja, com ações, estimulou a imaginação e a imaginação estimulou o corpo, considerando também o pensamento de Laban e seu sistema que relaciona o trabalho relativo do interno e externo. As crianças sempre experimentavam o trabalho com a representação de animais que faziam parte da história, refletindo como eram seus movimentos, a relação dos planos alto, médio e baixo a que eles pertenciam e também como estes elementos as influenciavam para narrar a história.

Era possível identificar as referências culturais indígenas nos desenhos e nas histórias de Sol. Cores, traços e formas davam arquitetura nas experiências propostas na oficina. As cores são uma metáfora dos ritmos diferenciados que iam dando vida à narração da história, os traços são às ações corporais que representavam os gestos dos personagens com precisão e com energia e as formas eram como a história era materializada e apresentada pelo espaço, juntando corpo/movimento, história na voz narrada e o faz de conta em um espaço constituído em alguns momentos como cênico, ou o ambiente lúdico formado pelo contexto da história. Seu corpo, ao experimentar as ações 
de Laban, abriu-se para um leque de possibilidades expressivas, ou seja, novas formas de utilizar o corpo de forma lúdica, como por exemplo, à ação de Laban chicotear, foi transformada no voo do passarinho que ganhava força para ir mais alto, e de novas leituras para a história que o grupo criou. Assim como os desenhos criados para tentar estabelecer uma relação entre história e corpo.

Essas são percepções observadas através da experimentação com as práticas de esforço, ação e espaço propostas por Laban. Sol, assim como as outras crianças, modificou, interpretou e significou da sua própria forma o espaço e as ações, dando vida a história com a utilização dos movimentos. Talvez, ela não tivesse a total consciência de suas ações em relação ao movimento e ao narrar da história, no âmbito de contribuição de um para o outro. Contudo, era visível como os movimentos contribuíam para a expressividade de Sol e das outras crianças que participaram da oficina.

Durante os encontros foram utilizados balões e fitas de papel crepom, objetos que contribuíram para a experimentação dos movimentos. Estes objetos trouxeram materialidade às ações e à história aos corpos. Tais objetos davam forma também aos personagens, momento que o imaginário das crianças era amplamente trabalhado. Cada participante podia escolher qual objeto queriam experimentar, depois elas agregavam esse objeto ao movimento dando possibilidades de ele ser o próprio personagem, mostrando isso ao narrar a história e também quando esse objeto era uma extensão de seu corpo, como no exemplo citado acima onde Sol narrou o passarinho que voava a partir da ação de chicotear, neste momento ela estava utilizando as fitas como objeto que mostrava também ser a composição do pássaro ou suas asas que tentavam bater mais forte e voar. Neste caso a fita acabou atribuindo mais vida e ludicidade aos movimentos de chicotear. A expressão da identidade também se evidencia na experiência com o Sistema do Movimento de Laban: "é o imaginário que, por meio do processo de simbolização, define as competências simbólico-organizacionais dos indivíduos e dos grupos, organizando as experiências e as ações humanas" (TEIXEIRA, 2006, p. 217). 
Portanto, com as organizações e descobertas, reforçamos a importância desse sistema em vários âmbitos educacionais, seja na escola ou em comunidades, pois, "a arte do movimento está presente em todas as cerimônias e rituais e é parte das qualidades do orador em qualquer tipo de oratória e ato público" (LABAN, 1990, p. 18). Nesse caso, isso reflete nos momentos que as crianças narravam suas histórias utilizando seus corpos através das ações de movimento. A importância desse sistema fica clara quando entendemos seu propósito de descoberta individual e sem a padronização de movimentos para um estilo artístico, nesse sentido, o trabalhar possibilitou caminhos ao não determinar formas rígidas a serem seguidas, dando autonomia as crianças para escolherem e transformarem os jogos e brincadeiras propostas.

Laban "buscou uma educação por meio do movimento, esse por sua vez, podendo ser também influenciado pelo meio ambiente, pelo contexto de quem se move" (RENGEL; LUCENA, 2015, p. 2). Essa educação por meio do movimento que o autor coloca é uma forma de expressão que pode estar ligada à vários princípios, no caso de Sol, às ações, à história, aos objetos e à vivência humana. Portanto, em todos os momentos que as crianças (umas em maior grau que outras) começavam suas experimentações com o sistema, automaticamente elas estavam ligadas por alguma referência interna/externa, à qual contribuíram e potencializavam os seus corpos que narraram a história.

\section{ALGUMAS CONSIDERAÇÕES}

Laban sistematizou um caminho para que cada indivíduo possa encontrar e se redescobrir como o corpo que é. Acreditamos que os profissionais da área da arte-educação também precisam compreender suas relações no ensino aprendizagem que é a maior ponte da construção do conhecimento entre indivíduos. É preciso quebrar os paradigmas de que os professores/facilitadores só tenham o papel de transferirem o conhecimento. A aprendizagem precisa gerar sentido para as crianças relacionando com o mundo que as rodeiam, propondo que os indivíduos façam parte da construção desse saber. 
As ponderações de Freire nos fazem refletir sobre o papel do professor. Cada indivíduo carrega conhecimentos, e o contato com o professor/facilitador deve oferecer subsídios para que este conhecimento se aprofunde e se expanda. Freire (2017, p. 47) diz: "devo estar sendo um ser aberto a indagações, à curiosidade, às perguntas dos alunos, a suas inibições; um ser crítico e inquiridor, inquieto em face da tarefa que tenho - a de ensinar e não a de transferir conhecimento". Esse pensamento do autor dialoga com o de Laban. Os dois propõem que o educando que esteja em processo de aprendizagem construa seu conhecimento junto ao professor. Essa construção conjunta de conhecimento entre educador e educando exige o fator que consideramos o mais relevante: o respeito, como afirma Freire (2017, p. 58), o "respeito à autonomia e à dignidade de cada um é um imperativo ético e não um favor que podemos ou não conceder uns aos outros".

Acreditamos na importância de um olhar minucioso à cada indivíduo compreendendo-o como agente e sujeito de suas experiências e da construção de conhecimento. Não delimitar um objetivo definido, mas propor meios, caminhos, proporcionar oportunidades para que possam significar e ressignificar suas próprias histórias. No caso da Aldeia Jaguapiru, foi a primeira vez que uma manifestação teatral com viés educacional aconteceu naquele espaço, com as crianças indígenas em sua comunidade, fora das escolas.

Nogueira (2009, p. 181) também discute o lugar dos aspectos estéticos no teatro na comunidade. Apesar de não serem foco principal do trabalho, é importante que estejam presentes a partir da cultura da comunidade, sem qualquer tipo de julgamento estético. Se acreditarmos que o fazer teatral é a redescoberta de si, considerar todas as formas expressivas que os indivíduos apresentam é parte fundamental nas práticas teatrais.

Nosso intuito com a oficina de teatro na aldeia não foi o de instrumentalizar tecnicamente as crianças e habilitá-las como profissionais do teatro, mas alimentar esteticamente as dramatizações que já existiam naquela comunidade, e oferecer a oportunidade às crianças de serem protagonistas de suas próprias histórias também no fazer teatral. Assim, afirmamos a impor- 
tância do indivíduo se conscientizar e se posicionar perante sua cultura de forma ativa e ética, expondo sua identidade e reafirmando a integração com sua comunidade.

\section{REFERÊNCIAS}

ANDRADE, M. de. Ação dramática, movimento funcional e teoria do esforço: origens do pensamento teatral na obra de Rudolf Laban. Urdimento (UDESC), v. 11, p. 169-176, 2008.

BARBA, E; SAVARESE, N. A arte secreta do ator: Dicionário de Antropologia Teatral. Campinas, SP: Hucitec-Unicamp-Edusp, 1995.

ESSLIN, M. Uma anatomia do drama. Rio de Janeiro: Zahar Editores, 1978.

COHEN, Anthony. The Symbolic Construction of Community. Londres: Routledge, 1985.

FREIRE, Paulo. Pedagogia do Oprimido. Rio de Janeiro: Paz e terra, 1980.

. Pedagogia da Autonomia: saberes necessários à prática educativa. 55. ed. Rio de Janeiro: Paz e Terra, 2017.

KERSHAW, B. The Politics of Performance: Radical Theatre as Social Intervention. Londres: Routledge, 1992.

KOUDELA, I. D.; ALMEIDA JÚNIOR, J. S. de. Léxico de pedagogia do teatro. São Paulo: Perspectiva: SP Escola de Teatro, 2015.

LABAN, R. Dança Educativa Moderna. São Paulo: Ícone, 1990.

LABAN, R. Domínio do movimento. 5. ed. São Paulo: Summus, 1978. 
MARQUES, I. Revisitando a dança educativa moderna de Rudolf Laban. Sala Preta, v. 2, p. 276-281, 26 nov. 2011.

NOGUEIRA, M. P. Teatro e Comunidade. In: FLORENTIONO, Adilson; TELLES, Narciso. (Org.). Cartografias do Ensino do Teatro. 1ed.Uberlândia: UDUFU, 2009, v. 1, p. 173-183.

RENGEL, L. P.; LUCENA, A. S. de. Ação corporal labaniana com respeito ao comum. In: IV encontro científico da associação nacional de pesquisadores em dança - ANDA 2015, Santa Maria/ RS. Formação em Dança, 2015. p. 1-9.

RENGEL, L. P.; OLIVEIRA, E.; GONÇALVES, C. C. S.; LUCENA, A.; SANTOS, J. F. dos. Elementos do movimento na dança. Salvador: UFBA, 2017.

TEIXEIRA, M. C. S. Pedagogia do imaginário e função imaginante: redefinindo o sentido da educação. Olhar de professor. Ponta Grossa, v. 9, n. 2, p. 215-227, 2006. 